\title{
The impact of physical and psychosocial risks on employee well-being and quality of life:
}

\section{The case of the mining industry in Ghana}

Published in: Amponsah-Tawiah, K., Leka, S., Jain, A., Hollis, D., \& Cox, T. (2014). The impact of physical and psychosocial risks on employee well-being and quality of life: The case of the mining industry in Ghana. Safety Science, 65, 28-35.

Author revised manuscript - pre-publication version.

\begin{abstract}
While in recent years there has been a growing awareness among mining companies of the need to address physical injuries and environmental issues, there remains a lack of knowledge about how psychosocial risks independently and in conjunction with physical risks affect the health, general well-being and quality of life of mine workers. A cross sectional survey was administered to 330 employees of five large scale mining companies producing three different mineral products (gold, manganese and bauxite) to examine physical and psychosocial hazards in the Ghanaian mining industry and their consequences for the quality of life and general well-being of employees. Responses from 307 participants showed mining equipment, ambient conditions, and work demands and control as being significant predictors of quality of life and general well-being after controlling for demographics. Age as a demographic variable also had important implications, with older workers experiencing better well-being and quality of life. Implications of findings for the mining sector in Ghana and other developing countries are further discussed which may serve as a starting point towards developing further initiatives in this area.
\end{abstract}

Keywords: well-being, quality of life, physical and psychosocial risks, mining, developing country 


\section{Introduction}

Mining involves the extraction of valuable minerals or other geological materials from the earth, usually from an ore body, vein or seam (Pule, 2011). Whether this is achieved underground or at ground level, mining exposes workers to potentially hazardous environments and conditions using potentially hazardous tools and materials (Pule, 2011), with a high incidence of injury recorded across all mining divisions (Ghosh et al., 2004).

Ghana has a rich natural resource of minerals. Gold, diamonds, manganese ore and bauxite are all produced in vast quantities from large-scale mines which are predominantly foreign owned and internationally run (Human Rights Clinic, 2010). In 2010 the mining industry contributed over $49 \%$ of the country's gross foreign exchange earnings (Owiredu, 2011). Gold remains a particularly lucrative export and in 2009 Ghana maintained its position as the ninth highest gold producing country in the world, with an output of 2,930,328 ounces producing revenue of US $\$ 2,842,821,528$ (The Ghana Chamber of Mines, 2009). The legal Ghanaian mining industry employs over 12,000 people across a wide spectrum of roles, with 98\% of those employed being Ghanaian nationals (Owiredu, 2011).

\section{Health and safety risks in the physical work environment in mines}

All people who work in mines have the potential to be exposed to various physical, chemical, mechanical, biological and psychosocial risks (Pule, 2011). For example, noise can be an important issue and with the increased mechanisation of mining is omnipresent from a multitude of practices including; boring, drilling, blasting, cutting, materials handling, ventilation, crushing, conveying and ore processing (Donoghue, 2004). Without adequate ear protection high levels of noise can directly damage the middle and inner ear canals and impair hearing, with this impairment in some individuals at 25dB (Genesove, 2010). Adequate ear protection is particularly important in the mining sector as noise level range from the lowest 
midpoint estimate of $88 \mathrm{~dB}$ for cutting machines and the highest being $117 \mathrm{~dB}$ for pneumatic percussion tools (McBride, 2004). In addition to objective exposure levels, psychological reactions can be a non-auditory health effect of noise (Smith, 1991). Less severe dB levels, if prolonged can give rise to the experience of stress and anxiety, irritability and tension, thus increasing fatigue and impairing the efficiency of worker performance (Leka and Jain, 2010).

Though exposure to noise is a significant hazard, accidents and dust both overshadow noise as a cause of mortality and morbidity within mines (McBride, 2004). Common accidents include rock fall, fires, explosions, mobile equipment accidents, falls from height, entrapment and electrocution (Donoghue, 2004).

A review of the number of acute traumatic injuries (which either resulted in more than three days' absence from work, a loss of consciousness, or death) of gold miners in a mining company in the Ashanti region of Ghana between October 1996 and August 2003 showed by far the greatest cause of injury was from moving or falling objects (58.4\%). Of all the accidents recorded and reported to the Mines Inspectorate, 79\% occurred in underground work (Sutherland, 2011).

Dust is ubiquitous in mining, as the work involves breaking rocks and extracting soil (Pule, 2011). The resultant pebbles and dust can cause physical and physiological harm. Dust can enter the eyes if they are not adequately protected damaging vision and can also cause various serious skin irritations. Inhalation of dust can also culminate in various respiratory conditions. Crystalline silica is the most abundant compound in the earth's crust and rock may contain $30 \%$ of silica or more. Silica exposure may occur in any mining operation as respirable particles form when the rock is drilled, blasted, crushed or pulverized and is dispersed through wind, vehicle traffic and earthmoving machinery (Genesove, 2010) and gold miners are particularly at risk of exposure to silica as it is mainly found in quartz rocks. The effects of prolonged exposure to crystalline silica do not manifest immediately. Silicosis is a scarring 
disease of the lung from inhalation and a lengthy period of time can pass before those exposed show a significant departure from their normal state of health (Genesove, 2010).

Long term effects include chronic obstructive pulmonary disease (Donoghue, 2004), tuberculosis, connective tissue and kidney diseases, emphysema and chronic bronchitis (Genesove, 2010). Evidence has also shown accelerated silicosis in rheumatoid arthritis and of renal disease following prolonged exposure and there is also evidence that it can lead to lung cancer (Steenland et al., 2001).

Heat is also a serious hazard, for both surface and underground mining. Dependent on the nature of the environment the heat can be dry or wet, with surface mining associated with solar heat or cold temperatures, which have risks of heath stroke and chill respectively. Humidity is a significant risk in underground mines. With the rock temperature increasing $1^{\circ} \mathrm{C}$ every 100 metres in depth (Genesove, 2010) and increasing geothermal gradient along with auto-compression of the air chamber further increases the mine temperature (Donoghue et al., 2000).

In deep South African underground gold mines fatal heat stroke has been a significant problem and heat exhaustion remains a persistent risk in deep underground mining. Miliaria rubra, 'mucker's mange' or 'prickly heat' as it is otherwise referred to, remains problematic in deep underground mines (Donoghue and Sinclair, 2000).

Vibration also presents a significant physical risk in mining (Donoghue, 2004) be it whole body vibration which is commonly experienced whilst operating mobile equipment, for example scrapers and diggers, or through the use of vibrating tools, such as air leg rock drills which can cause hand-arm vibration syndrome. 


\section{Psychosocial risks in mines}

Poor working conditions can result in a poor person-environment fit with an increased risk of work stressors causing mental ill health and occupational injuries (Li et al., 2001). In addition to poor working conditions, the perception of a poor working environment and poor management and supervision also has a significant influence on mine workers' occupational injuries; in particular low supervisory support for health and safety with a preoccupation for achieving production targets can affect worker behaviour and overall well-being (Ghosh et al., 2004).

The age of a worker also mediates the relationship between the work environment and risk of injury due to poor person-environment fit. For example, Ghosh and colleagues (2004) found that older mine workers (over 45 years) were at a greater risk of having occupational injuries, which was attributed to a decrease in their physical and mental abilities which subsequently diminished their ability to perform highly demanding tasks properly and be sufficiently attuned and alert to environmental mining hazards (Ghosh et al., 2004). Other studies (Bazroy et al., 2003; Chau et al., 2002; Ghosh et al., 1998) report that that younger workers can also be at a greater risk of mining injuries as their lack of experience can contribute to a lack of knowledge which leads to a greater propensity to engage in risk taking behaviours.

Within mining sector, workers are exposed to a variety of work demands and pressures due to the hazardous working environment. The job role itself and the interaction between the tasks that need to be performed and the hazardous environment, can severely challenge the potential of a mine workers' ability to cope with these work demands and pressures, which over time can cause physical and psychological harm (Cox et al., 2000).

Jobs, particularly those in underground mines, have unsurprisingly been reported to be stressful (Ghosh et al., 2004). The unpredictability of the dynamic environment in which mine 
workers operate, characterised by the constant and regular tampering of soil and rock leads to a continuous presence of danger, particularly as the work proceeds deeper into the earth's surface (Pule, 2011). Such dynamism in the working environment makes it difficult for workers to recognise and control hazards. This inability to notice danger increasing the chances of accidents which can in turn lead to post-traumatic stress from personal injury or from witnessing injury or death of co-workers.

There are also a multitude of external elements, for example heat and noise which workers have little control over. In addition with the increased mechanisation of plant equipment and tools, the work performed can often be repetitive and monotonous with workers having little control over the pace of their work. Mining is also associated with long and awkward hours (Pule, 2011). Long shift patterns, coupled with the physical factors outlined above can result in worker fatigue. This type of work is typically characterised by high job demands, low control and potential effort-reward imbalance, three psychosocial risk factors that have been identified for mental and physical health problems (Leka and Jain, 2010). Indeed, findings from the Fourth European Working Conditions survey (Eurofound, 2007) indicated that employees who are exposed to a high level of physical risk are more likely to report that their health is at risk as a result of their work (Leka and Jain, 2010).

Across occupational sectors, there is evidence to indicate that poor working conditions can affect both workers' experience of stress and their psychological and physical health (Warr, 1992). For example, even in a study from the 1970 s, in a comparison of UK coal miners with workers in jobs of similar status, Althouse and Hurrell (1977) found that despite a difference in the physical dangerousness of the two job types, there were no differences in the experience of stress in both types of workers, however mine workers did report significantly higher symptoms of irritation and somatic complaints. 
With regards to mining specific studies, since the Althouse and Hurrell (1977) study over 40 years ago very few studies have investigated the hazard-stress-harm pathway, with more recent studies (e.g., Ghosh et al., 2004; Sutherland, 2011) focussing on the more easily recordable and verifiable physical outcomes of mine workers' health: occupational injuries. A better understanding of the association between different types of risks in the mining environment and the general health and well-being of employees and their quality of life may therefore offer opportunities for the development of appropriate occupational health and safety management programmes and intervention strategies for health and safety promotion. This study therefore had the primary objective of examining psychosocial and physical hazards in the Ghanaian mining industry and their relationship to the experience of quality of life, health and well-being of employees.

\section{Methodology}

Mining is globally recognised as one of the most hazardous sectors (ILO, 2010). Investigating the safety environment in this sector is particularly challenging, even more so in a developing country context. This therefore called for an innovative approach in gaining access and in addressing the various variables of interest in a non-obtrusive manner. In this study, the concept of corporate social responsibility (CSR), which includes employee well-being issues as an integral part (HSE, 2005), and is of interest to mining companies was used to gain access in the Ghanaian mining industry.

Initial semi-structured interviews were conducted with 35 key stakeholders in the Ghanaian mining industry. Participants were nine managers in charge of health, safety and environment in nine different mining companies, nine managers in charge of community relations, one manager in charge of corporate social responsibility, nine union executives from the different companies, a manager at the Ghanaian Chamber of Mines, two principal inspectors of mines at the Minerals Commission, an executive member of the mine workers union responsible for 
health safety and environmental issues in the mines, an executive officer of a community based mining advocacy organisation, a manager of an international NGO/CSO and a contractor/supplier to the mining industry. The rationale for targeting key personnel at the interface of identified stakeholder organisations stems from leadership theories, which describe effective leaders as managing from the boundary (Druskat \& Wheeler, 2003). Thus these participants holding key positions are satisfactory sources of information regarding the policies and operations of their organisations. Information gathered through the interviews provided the basis for the design of a quantitative study and further offered a qualitative context to the quantitative data collected. The quantitative study involved the administration of a survey to a sample of employees from large scale mining companies. This paper presents findings from the quantitative study which involved the administration of a structured questionnaire to non-management staff in selected mining companies.

\subsection{Procedure}

The mixed method sampling strategy - a combination of probability and non-probability sampling techniques (Teddlie and Yu, 2007), also known as stratified purposive sampling, was used to select large scale mining companies operating in the minerals sector for more than four years. This was achieved through the effective collaboration of the Ghana Chamber of Mines. Nine companies operating in Ghana met the selection criteria and of these five companies agreed to participate in the study. Participants were then randomly selected, from these five large scale mining companies, by using stratified random sampling technique during tool-box briefings before the commencement of work. All mine employees attended the tool-box briefings and were stratified on the basis of pattern of work, role in the organisation (technical or administrative). Due to small cohorts, managers and female employees were excluded from the sample. The selected participants were administered the questionnaire survey to complete and return to the researchers. Questionnaires were anonymous and participants were assured of strict confidentiality and anonymity of their responses and treatment of the information they provided according to the Data Protection 
Act (1998). Ethical approval of the study was gained by the Ethics Committee of the University of Nottingham.

\subsection{Sample}

A total of 330 questionnaires were administered to selected participants. The companies cut across three different mineral products (i.e., gold, bauxite and manganese). Out of the 330 questionnaires administered, 307 were correctly completed and returned representing a response rate of $93 \%$. The high response rate was basically due to the administration procedure adopted. This meant that participants did not have the flexibility of deferring their responses to a later date, a situation which accounts for low return rate in most questionnaire surveys.

Over half the respondents (51.5\%) fell within the age range of $26-40$ years, while $33.9 \%$ fell within the ages of 41-50 years, while nearly two thirds (64.5\%) worked in gold mines while $35.5 \%$ worked in non-gold mines (bauxite and manganese). Just over $70 \%$ of the participants had technical roles and were involved with mining operations while the others had administrative roles. The average tenure was 9 years, with over $50 \%$ of the participants reporting more than 5 years of experience in their current role. In terms of work pattern, $56.4 \%$ workers worked in variable shifts while $43.6 \%$ had fixed shifts and worked during the day.

\subsection{Measures}

The questionnaire was constructed on the basis of the literature to explore psychosocial and physical hazards in large scale mining industries in Ghana and their impact on the quality of life and general well-being of employees working in these mines.

Physical and Psychosocial Hazards: The section on physical hazards was developed by the research team on the basis of the literature and qualitative research conducted prior to the 
quantitative study. Items on the physical hazard scale included mine gases, mine fires, excessive noise, heat stress, poor visibility and dusty conditions. These were assessed on a five-point likert scale ranging from most problematic (5) to least problematic (1), where respondents indicated the extent to which each hazard posed a problem at their workplace. The internal reliability of this scale was $\alpha=.76$.

The section on psychosocial hazards was developed on the basis of existing a validated instrument and qualitative research conducted prior to the quantitative study. The items were developed based on COPSOQ dimensions (Kristensen et al, 2005), but both items and response format were modified within the present study. The measure included six items on high workload, lack of job security, poor colleague support, poor supervisory support, lack of job control and lack of role clarity to assess psychosocial hazards. Participants were asked to rate the items on a five-point likert scale ranging from most problematic (5) to least problematic (1), where respondents indicated the extent to which each hazard posed a problem at their workplace. This scale also recorded an acceptable internal reliability of $\alpha=.78$.

General Well-being: This was assessed using items from the Health Anxiety and Health Status sub-scales of the Health Orientation Scale (Snell, 1996). Four items on the Health Anxiety subscale were used: I feel anxious when I think about my health; I am worried about how healthy my body is; thinking about my physical health leaves me with an uneasy feeling; and I usually worry about whether I am in good health. They refer to anxiety feelings associated with the status of one's health. More specifically, these items are designed to tap on people's feelings of tension, discomfort and anxiety about their physical health and are rated on a five-point likert-type scale from not at all a characteristic of me (1) to very characteristic of me (5). Similarly, four items on the Health Status subscale were used: my body is in good physical shape; I am in good physical health; I become easily tired and I have difficulty in falling and staying asleep. They concern people's assessment of the physical status of their 
body. More specifically, these items are designed to measure the extent to which people assess their body as being in excellent and robust health and are rated in the same way as the Health Anxiety subscale. The scale recorded an internal reliability of $\alpha=.74$.

Quality of Life: This was a subjective evaluation measured on a five-point likert-type scale with ten items addressing Cummins (1997) seven domains of quality of life: material wellbeing, health, productivity, intimacy, safety, community and emotional well-being. Test-retest reliability and internal consistency analyses indicated that the scale has adequate reliability $(\alpha=.78)$.

\subsection{Data Analysis}

Data from the questionnaire survey were coded manually by assigning values to the various responses and entered into SPSS version 16.0 that was used for the data analysis. Exploratory factor analysis and hierarchical regression analysis were used to explore the various physical and psychosocial hazards and their effect on quality of life and well-being. An initial exploratory factor analysis was conducted to examine the data set and refine and reduce items to form a smaller number of coherent subscales. Through the exploratory process, large numbers of related variables were reduced to manageable numbers prior to their use in the hierarchical regression analysis (Ferguson and Cox, 1993). Multiple hierarchical regression was used to evaluate the relationship between the independent variables: psychosocial and physical hazards, and the dependent variables: general well-being and quality of life. Age of the worker, tenure, pattern of work, mine type and department were entered as control variables.

\section{Results}

\subsection{Factor structure}


Principal component analysis was conducted on each measure discussed in section 4.3. The physical hazard scale revealed three components: mining equipment, ambient conditions and general mining conditions and the psychosocial hazard scale revealed two factor components: 'work demands and control' and 'social support and security', as presented in Table 1 . The quality of life scale also revealed two factor components: society determined quality of life and resource dependent quality of life, presented in Table 2 .

\section{INSERT TABLE 1 AND TABLE 2 HERE}

The eight items of the general health and well-being scale were also subjected to a principal component analysis. The results revealed the presence of a simple structure with the two components showing a number of strong loadings, and all variables loading substantially on only one component. The two factor solution explained a total of $65.41 \%$ of the variance. Although interpretation of the scale is consistent with the two factor subscales of the Health Orientation Scale (Snell, 1996) (i.e., health anxiety and health status), in this study, the data set loaded 6 items on the health anxiety subscale and 2 on the health status subscale as opposed to the original 4 items on each. The two items loading on the health status subscale were almost synonymous. Therefore the general well-being scale was maintained as a single factor.

\subsection{Psychosocial and physical mine hazards and general well-being}

The relationship between the two psychosocial factors and general well-being was assessed in a hierarchical multiple regression. The analysis with general well-being as the dependent variable was completed in three steps, with the control variables entered at the first step. The final model with the predictor variables was significant with $\mathrm{F}(7,299)=4.573, \mathrm{p}<.001$ accounting for $9.7 \%$ of the variance $\left(\mathrm{R}^{2}=.097\right)$. 
Even though low support and job insecurity showed a significant positive relationship with poor general well-being on the zero order correlation, it did not contribute significantly to the regression. Interestingly, age had a negative relationship with poor general well-being ( $\beta=$ $.208, \mathrm{p}<.01)$, suggesting that as employees advanced in age, their health and well-being improved. This finding may reflect the responses of older employees within the organisation most of whom have regular patterns of work (straight day) and are given light schedules, which may not impact negatively on their health and well-being. High work demands and low job control showed a positive association with poor general well-being $(\beta=.168, p<.01)$, indicating that as employees experienced higher demands and less control over their work, their general health and well-being worsened.

Similarly, the relationship between general well-being and the three physical hazard factors (i.e., mining equipment, ambient conditions and general mining conditions) was analysed using hierarchical multiple regression. The final model with the predictor variables was significant with $\mathrm{F}(8,298)=8.990, \mathrm{p}<.001$ accounting for $19.4 \%$ of variability $\left(\mathrm{R}^{2}=.194\right)$. The results indicated that even though all the three physical hazard factors had significant positive relationships with poor general well-being on the zero order correlation, only hazardous mining equipment $(\beta=.254, \mathrm{p}<.001)$ and poor general mining conditions $(\beta=.184, \mathrm{p}<.01)$ contributed significantly to the prediction of poor general well-being. As was expected, both factors had positive relationships with poor general well-being indicating that hazardous mining equipment and deterioration in general mining conditions were associated with a decline in the general well-being of employees. Age on the other hand showed a significant negative relationship $(\beta=-.223, \mathrm{p}<.01)$, highlighting that as the age of employees increased, their general health and well-being improved.

\subsection{Psychosocial and physical mine hazards and quality of life}

Each of the two dimensions of the quality of life scale (society determined quality of life and resource dependent quality of life) were assessed as dependent variables in four separate 
hierarchical regression models. Psychosocial hazards (support and security and work demands and control) were entered as predictors in the first two models, while physical hazards in mines (mining equipment, ambient conditions and mining conditions) were entered as predictors in the other two models. Age of the worker, tenure, pattern of work, mine type and department were entered as control variables in each regression analysis.

The regression model analysing the relationship between psychosocial hazards on society determined quality of life, indicated that neither psychosocial hazard significantly contributed to the variance; nor did they show any relationship with society determined quality of life. The final model was however significant with $\mathrm{F}(7,299)=4.330, \mathrm{p}<.001$, accounting for $9.2 \%$ of variability $\left(\mathrm{R}^{2}=.092\right)$. Mine type $(\beta=.288, \mathrm{p}<.01)$ and age $(\beta=.145, \mathrm{p}<.05)$ had positive associations with society determined quality of life, highlighting that mine workers from non-gold mines and older workers reported higher quality of life.

In the analysis of the relationship between psychosocial hazards on resource dependent quality of life, the final model with the predictor variables was found to be significant with $\mathrm{F}$ $(7,299)=5.759, \mathrm{p}<.001$, explaining $11.9 \%$ of the variance $\left(\mathrm{R}^{2}=.119\right)$. Both 'low support and job insecurity' and 'high work demands and low job control' significantly contributed to the variance. Low support and insecurity $(\beta=-.118, \mathrm{p}<.05)$ and high work demands and low control $(\beta=-.232, p<.01)$ had significant negative associations with resource dependent quality of life, indicating that lack of support from colleagues and supervisors and job insecurity as well as higher demands and lack of control over work, adversely affected the resource dependent quality of life of workers.

The final regression model analysing the relationship between physical hazards and society determined quality of life was statistically significant, $F(8,298)=6.116, p<.001$, accounting for $14.1 \%$ of variance $\left(\mathrm{R}^{2}=.141\right)$. General mining conditions did not explain the variance in the model. However, poor ambient conditions $(\beta=-.130, \mathrm{p}<.05)$ and hazardous mining 
equipment $(\beta=-.252, \mathrm{p}<.001)$ had a significant negative relationship with society determined quality of life which indicates that deterioration in the ambient conditions in the mines and the hazards posed by mining equipment adversely affected the quality of life of employees. Age of the miner $(\beta=.135, \mathrm{p}<.05)$ and mine type $(\beta=.262, \mathrm{p}<.01)$ had positive associations with society determined quality of life, again highlighting that workers, and mine workers from non-gold mines reported higher quality of life.

Analysis of the relationship between physical hazards and resource dependent quality of life, showed that the final model was significant with $\mathrm{F}(8,298)=7.270, \mathrm{p}<.001$, accounting for $16.3 \%$ of variance $\left(\mathrm{R}^{2}=.163\right)$. Poor ambient conditions $(\beta=-.185, \mathrm{p}<.01)$ and hazardous mining equipment $(\beta=-.271, \mathrm{p}<.001)$ had significant negative associations with resource dependent quality of life. Thus employees perceived deteriorations in ambient conditions and mining equipment as having adverse effects on the resources needed to ensure a better quality of life. Hazards posed by mining equipment, predicted the relationship better as compared to hazards posed by poor ambient conditions. Interestingly, general mining conditions did not have a significant association with resource dependent quality of life.

\section{Discussion}

A number of research questions have been addressed in this study that relate to the broad context of quality of life and well-being in the Ghanaian mining industry and within the participant organisations. Regarding general well-being in the Ghanaian mining industry, high work demands and low control at work had a negative effect on employees' experience of health and well-being. This finding is consistent with the job strain 'demand-control' hypothesis, which states that the combination of high job demands and low decision latitude results in worse health (Karasek and Theorell, 1990). Lack of control in the workplace is a core independent variable for predicting the outcome variables of stress, health behaviours and ill-health consequences (Leka and Jain, 2010). Low decision latitude, which falls under 
the second of the 'demand-control' dimensions, is the experience of low control or loss of control at work, and this has been shown, in a variety of studies, to be associated with a wide range of mental health outcomes, namely stress, anxiety, depression, apathy and exhaustion, low self-esteem and an increased incidence of cardiovascular symptoms (Leka and Jain, 2010).

As outlined in the introduction, there is a plethora of dynamic physical demands placed upon mine workers. Within the workplace when workers perceive the demands as being greater than their capacity to cope, either through lack of knowledge, skills or control over their work then they are likely to perceive their work situation as stressful (Cox et al., 2000). The present findings suggest that employees with moderate workloads, within their control experienced better health and well-being than their colleagues with excessive workloads and little control. The fact that there is an optimum level of work demands beyond which the health and wellbeing of employees will decline is flagged in the study and has been supported in previous studies. This is important for work design and policy formulation especially amongst Ghanaian mining companies as the majority of their health and safety policies focus on physical and environmental factors and neglect the psychosocial work environment.

Mining equipment was also found to have a negative effect on the experience of well-being of employees. To maintain competitive advantage within the modern mining sector heavy machinery is a pre-requisite for mine exploration. However, as noted, humans have to interact with this equipment to complete the production cycle. This involves a complex physical and mechanical process which poses a threat to the physical and psychological health and wellbeing of employees. As outlined, the use of such equipment generates a large variety of pollutants (e.g., noise, dust and chemicals) which, if not properly controlled, have the potential to cause serious health hazards for employees and affect their well-being. This situation is exacerbated by an influx of obsolete and outlawed equipment dumped on mining companies in Ghana by parent companies who operate in the developed world where 
such equipment have been outlawed. Obsolete equipment generates very harmful gases that can displace the oxygen in the mine, causing asphyxiation (NIOSH, 2007). The outrageous noise created by obsolete equipment in the mines combined with the enclosed workspace that characterises underground mines increases the likelihood of hearing loss (Peterson et al., 2006).

This perhaps explains why, specifically, mining equipment had a more devastating effect on the well-being of employees than the general mining conditions; they engendered the poor conditions which gave rise to poor health and well-being. Employees will also require extra energy to operate/interact with obsolete equipment to achieve the desired output. This makes the job longer and harder, a situation which can lead to frustration, work-related stress and poorer well-being. It is evident from the findings and the explanations given that the relationship between mining equipment and well-being, whether mediated or direct is a negative one and calls for attention from policy makers on the importation and use of mining equipment.

A further study finding was that the general mine conditions (for example, gasses, fires and inadequate ventilation) had a negative effect on the experience of well-being amongst employees. Insufficient ventilation heightens the ill effects of harmful gases, heat and dust in underground mines which affect the health and well-being of employees. In surface mining, the blasting, crushing, drilling and hauling process coupled with the obsolete equipment and their resultant release of harmful gasses and dust particles creates a stressful environment for employees.

Whether over ground or below the sub-surface the extremes of physical work conditions, for example temperature and humidity, are associated with the experience of stress (e.g., Holt, 1982; Szabo et al., 1983). With other physical hazards, it is not only their actual presence but the perceived threat of presence which is associated with the experience of stress (Leka and 
Jain, 2010). In such a dynamic environment as the mine industry the perception of threat appears great.

Within the current sample, older employees (i.e. older than 41 years) indicated that they experienced better well-being compared to their younger colleagues. Thus, in attributing rationale to this finding it may be that older workers' attitudes to health and well-being become refined and acclimatised after prolonged and continuous exposure to physical and psychosocial risks. Alternatively, because in the current sample older workers who had been on the job for a longer duration were given less stressful jobs later in life, telescoping effects may be present, with backward telescoping occurring where workers perceive recent events to be representative and a true account of previous events (Neter and Waksberg, 1964). The needs of older workers have been demonstrated to be different to their younger colleagues, particularly with regards to increased exposure to psychosocial risks at work, namely less training over a similar period of time, decreased opportunities to gain further knowledge, expertise and develop new skills, less opportunities for task rotation, less support from supervisors, less access to professional development and discrimination in terms of selection, career development, learning opportunities and redundancy (Leka and Jain, 2010). Thus, whether older workers continue to perform the same type of work as their younger colleagues or allowances are made, differential environments and conditions can lessen or heighten older workers' exposure to psychosocial risks, and these considerations need to be taken into account when designing work and formulating occupational health and safety policies.

Furthermore, employees perceived their quality of life to be influenced not only by the resources available to them, but also by society. As with the resource dependent quality of life, quality of life as determined by the society was also affected by the ambient conditions of the mines as well as the mining equipment used in the process. The dust particles and noise levels generated by the huge and obsolete mining equipment transcends the confines of the 
immediate mining environment to include the communities within which they are located. A report by the Human Rights Clinic, The University of Texas School of Law, (2010) examined if and how communities are affected by gold mining in the Tarkwa region of Ghana. The report found that mining companies' ongoing presence created an overwhelmingly negative impact via environmental degradation, illnesses and dangerous working conditions upon the lives of those in affected communities. Surface mining was found to result in frequent chemical spills which have either dried up or irretrievably contaminated water sources in the area. Constant blasting caused not only dust pollution, but also damaged the structures of community buildings and the threat of blasting was reported to be a continual stressor on the community. As a result of these practices members of the community within the vicinity of the mine reported frequent headaches and dizziness because of air pollution due to blasting and air pollution due to chemicals while doctors in Obuasi Government medical facilities "acknowledged that some of the diseases prevalent in communities in the periphery of the mine are in part attributable to mining" (p.41, The Human Rights Clinic, The University of Texas School of Law, 2010).

In addition, there are the societal repercussions of these companies' practices, with many community members left with few, if any, employment options after losing their farmland to the companies and the gold mines often cannot provide enough jobs to absorb the total number of those agricultural workers who have been laid off (Akabzaa and Darimani 2001). The report concluded that mining companies did little to prevent, remedy or compensate for the ill effects of the working practices outlined above.

Although in comparison to the Ghanaian average wage mining employees are paid more than their counterparts in other sectors, pay alone does not sufficiently compensate workers for the various physical and psychosocial hazards they encounter in the workplace, leaving employees with very few physical and material resources needed to improve their quality of life. Indeed, using the salaries of employees (financial resource) as the sole determinant of 
quality of life as has been done in some studies has been proven to be erroneous. The society within which organisations operate and where their employees reside has been found to play a role in the determination of quality of life. Organisations can therefore not continue to use monetary incentives as the only resource to improve the quality of life of employees. Other organisational interventions as work design and support that allows workers the time and space to relax, release other resources such as time and energy needed to experience a better quality of life.

\section{Conclusion}

The introduction and increased use of safety management systems (particularly in developed countries) have done much to address the physical hazards in hazardous industries such as mining, where physical injuries are more readily recordable and verifiable. However, there is a paucity of both awareness and knowledge of how psychosocial risks can have longer term effects on mine workers' ill health, general well-being and quality of life. In particular, the increasing mechanisation of the industry results in a quickening of work pace for miners, which often they have little control over. This, coupled with the dynamism of the hazardous environment in which the work is carried out, which is exacerbated and prolonged by the often obsolete equipment in use in developing countries, constitutes a considerable threat to employee well-being. In addition, in countries where companies are not held socially responsible for their practices, workers often have an additional risk of being associated with the harm their employer exerts upon the community and so workers can experience adverse effects from societal judgement.

Thus, interventions should be pitched, where possible, at the primary level to eliminate physical and psychosocial hazards at source. For example, the cessation of obsolete 'hand me- down' machinery should be a prerequisite as stated in Article 7 (a) of the ILO Safety and Health in Mines Convention, 1995 (No.176). Safety management control systems should also 
be in place (as stated in Article 6 of the same Convention) which though not completely eradicating the level of risk physical hazards pose, would serve as a mechanism to reduce the perception of threat and potentially reduce worker stress.

Finally, in addition to primary level interventions to manage psychosocial risks and combat work-related stress by taking actions towards better design, work organisation and management, secondary and tertiary interventions can also be beneficial to raise awareness and minimise the effect of stress related problems post occurrence through the management and treatment of symptoms of occupational disease and illness (e.g., Cooper and Cartwright, 1997; Hurrell and Murphy, 1996; LaMontagne et al., 2007).

\section{Limitations}

The use of a single-source self-report data in the study may be subject to common method variance issues as well as issues of social desirability bias. The wording of some items in the quality of life scale could derive socially desirable answers, even though the possibility of social desirability bias was low as the respondents were asked questions relating to the mining profession in general and not about their own behaviour or actions. Another limitation is the use of negatively worded (reverse-coded) items and positively worded items in the quality of life scale may have raise some methodological issues such as factor loadings which can take place not due to content but due to negative/positive presentation of the content (Podsakoff, MacKenzie, Lee, and Podsakoff, 2003). Therefore the findings in relation to resource dependent quality of life and society determined quality of life should be interpreted with caution. This limitation however does not have an impact on the overall findings that physical and psychosocial hazards have an adverse effect on the quality of life of mine workers.

Efforts were also made to address these limitations at the outset of the study. The measures used in this study were developed on the basis of the literature, existing validated instruments 
as well as qualitative research. All efforts were made to ensure that the measures were appropriate to the work and cultural context. Furthermore, previous studies also indicate that self-report measures of well-being and quality of life are related to independent observations of these variables and often include items which can elicit socially desirable responses.

Finally, the sample size and the cross-sectional design of the study were other limitations. Ideally, a larger scale longitudinal study would be employed to yield more reliable results. However, this is one of the few studies addressing both physical and psychosocial hazards as well as employee well-being and quality of life in the Ghanaian mining industry and serves as a starting point towards developing further initiatives in this area. 


\section{References}

Akabzaa, T., Abdulai, D., 2001. Impact of Mining Sector Investment in Ghana: A Study of the Tarkwa Mining Region. Paper presented at the Second National Forum in Accra, Ghana, May 7-9, 2001.

Althouse, R., Hurrell, J., 1977. An analysis of job stress in coal mining. Technical Report PB274796. Morgantown: West Virginia University.

Bazroy J., Roy G., Sahai A., Soudarssanane M.B., 2003. Magnitude and Risk Factors of Injuries in a Glass Bottle Manufacturing Plant. Journal of Occupational Health 45, 53-59.

Chau, N., Mur, J.M., Benamghar, L., Siegfried, C., Dangelzer, J.L., Francais, M., Jacquin, R., Sourdot, A., 2002. Relationships between some individual characteristics and occupational accidents in the construction industry: a case-control study on 880 victims of accidents occurred during a two-year period. Journal of Occupational Health 44, 131-139.

Cooper, C.L., Cartwright, S., 1997. An intervention strategy for workplace stress. Journal of Psychosomatic Research 43 (1), 7-16.

Cox, T., Griffiths, A., Rial-Gonzalez, E., 2000. Research on work related stress. Luxembourg: Office for Official Publications of the European Communities.

Cummins, R. A., 1997. Self-Rated Quality of Life Scales for People with an Intellectual Disability. Journal of Applied Research in Intellectual Disabilities 10,199-216.

Donoghue, A.M., Sinclair, M.J., 2000. Miliaria rubra of the lower limbs in underground miners. Occupational Medicine 50 (6), 430- 433.

Donoghue, A.M., Sinclair, M.J., Bates, G.P., 2000. Heat exhaustion in a deep underground metalliferous mine. Occupational and Environmental Medicine 57 (3), 165-174.

Donoghue, A.M., 2004.Occupational health hazards in mining: an overview. Occupational Medicine 54, 283-289.

Druskat, V.U., Wheeler, J.V. 2003. Managing from the boundary: The effective leadership of self-managing work teams. Academy of Management Journal, 46, 435-457.

EuroFound, 2007. The Fourth Working Conditions Survey. Dublin: Office for Official Publications of the European Communities.

Ferguson, E., Cox, T., 1993. Exploratory factor analysis: a user's guide. International Journal of Selection and Assessment 1, 84-94.

French, J. R. P., Rogers, W., Cobb, S., 1974. A model of person-environment fit. In: G.W. Coehlo, D.A. Hamburg \& J.E. Adams (Eds.), Coping and Adaptation. New York: Basic Books.

Genesove, L., 2010. Occupational Health Hazards in Mining \& Metallurgical Work. Paper presented at the Mining Health and Safety Conference 2010 in Sudbury, Ontario, Canada, April 20-22, 2010.

Ghosh, A.K., Bhattacherjee, A., Ray, S.C., 1998. An application of system dynamics in mine safety studies. Mineral Resources Engineering 7, 131- 147. 
Ghosh A.K., Bhattacherjee A., Chau N., 2004. Relationships of working conditions and individual characteristics with occupational injuries: A case-control study in coal miners. Journal of Occupational Health 46, 470 - 478.

Holt, R.R., 1982. Occupational stress. In: L. Goldberger \& S. Breznitz (Eds.) Handbook of Stress: Theoretical and Clinical Aspects. New York: Free Press.

Health and Safety Executive (HSE), 2005. Promoting health and safety as a key goal of the corporate social responsibility agenda. Research report 339. Sudbury: HSE Books. www.hse.gov.uk/research/rrhtm/rr339.htm (Feb. 22, 2012).

Human Rights Clinic, 2010. The Cost of Gold: Communities affected by mining in the Tarkwa region of Ghana. Austin: The University of Texas School of Law. http://www.utexas.edu/law/clinics/humanrights/docs/Ghana_report.pdf (Feb. 22, 2012).

Hurrell, J.J.Jr., Murphy, L.R., 1996. Occupational stress interventions. American Journal of Industrial Medicine 29, 338-341.

ILO, 1995. Safety and Health in Mines Convention (C 176).

http://www.ilo.org/ilolex/english/convdisp1.htm (Feb. 22, 2012).

Karasek, R.A., Theorell, T., 1990. Healthy Work, Stress, Productivity and the Reconstruction of Working Life. New York: Basic Books.

Kristensen, T.S., Hannerz, H., Høgh, A., Borg, V. 2005. The Copenhagen Psychosocial Questionnaire - a tool for the assessment and improvement of the psychosocial work environment. Scandinavian Journal of Work Environment \& Health, 31(6), 438-449.

LaMontagne, A.D., Keegel, T., Louie, A.M.L., Ostry, A., Landsbergis, P.A., 2007. A systematic review of the job-stress intervention evaluation literature, 1995-2005. International Journal of Occupational \& Environmental Health 13, 268-280.

Leka, S., Jain, A., 2010. Health Impact of Psychosocial Hazards at Work: An overview. Geneva: World Health Organization

Li, C.Y., Chen, K.R., Wu, C.H., Sung, F.C., 2001. Job Stress and dissatisfaction in association with non-fatal injuries on the job in a cross-sectional sample of petroleum workers. Occupational Medicine 51, 50-55.

McBride, D.I., 2004. Noise-induced hearing loss and hearing conservation in mining. Occupational Medicine 54 (5), 290-296.

Neter, J., Waksberg, J., 1964. A study of response errors in expenditure data from household interviews. Journal of the American Statistical Association 59, 18-55.

NIOSH, 2007. Mining Safety and Health Ventilation. Washington DC: National Institute for Occupational Safety and Health. http://www.cdc.gov/niosh/mining/topics/topicpage30.htm (Feb. 22, 2012).

Owiredu, D., 2011. Annual chamber of mines presidential review. 83rd Annual General Meeting of the Ghana Chamber of Mines. www.ghanachamberofmines.org/ (Feb. 22, 2012).

Peterson, J.S., Kovalchik, P.G., Matetic, R.J., 2006. A Sound Power Level Study of a Roof Bolter. Transactions of Society for Mining, Metallurgy, and Exploration 320,171-177. 
Podsakoff, P. M., MacKenzie, S. B., Lee, J.-Y., Podsakoff, N. P., 2003. Common method biases in behavioural research: a critical review of the literature and recommended remedies. Journal of Applied Psychology 88(5), 879-903.

Pule, T., 2011. Mining activities and occupational health and safety at work. African Newsletter on Occupational Health and Safety 21 (1), 4-7.

Sauter, S.L., Hurrell, J.J., Cooper, C.L., 1989. Job Control \& Worker Health. Chichester: Wiley \& sons.

Smith, A., 1991. A review of the non auditory effects of noise on health. Work \& Stress 5, 49-62.

Snell, W.E., 1996. The development and validation of the Health Orientation Scale: A measure of personality tendencies associated with health.

http://www4.semo.edu/snell/scales/HOS.htm (Feb. 22, 2012).

Steenland, K., Mannetje, A., Boffetta, P., Stayner, L., Attfield, M., Chen, J., Dosemeci, M., DeKlerk, N., Hnizdo, E., Koskela, R., Checkoway, H., 2001. Pooled exposure-response analyses and risk assessment for lung cancer in 10 cohorts of silica-exposed workers: an IARC multi-centric study. Cancer Causes Control 12, 773-784.

Sutherland, V.J., Cooper, C.L., 2000. Strategic Stress Management: An Organizational Approach. New York: Palgrave.

Sutherland, D.K.B, 2011. Occupational injuries in a gold mining company in Ghana. African Newsletter on Occupational Health and Safety 21 (1), 8-10.

Szabo, S., Maull, E.A., Pirie, J., 1983. Occupational stress: Understanding, recognition and prevention. Experientia 39, 1057-1180.

Teddlie, C., Yu, F., 2007. Mixed methods sampling: A typology with examples. Journal of mixed Methods Research 1, 77-100.

The Ghana Chamber of Mines, 2009. Performance of the mining industry in 2009. http://www.ghanachamberofmines.org/site/publications/ (Feb. 22, 2012).

Warr, P.B., 1992. Job features and excessive stress. In R. Jenkins \& N. Coney (Eds.), Prevention of Mental Ill Health at Work. London: HMSO. 
Table 1: Varimax Rotation of Three Factor Solution for Physical hazard items and Two Factor Solution Psychosocial hazard items

\begin{tabular}{|c|c|c|c|c|c|}
\hline \multirow[t]{2}{*}{ Item } & \multicolumn{5}{|c|}{ Component } \\
\hline & Mining Equipment & $\begin{array}{c}\text { General Mining } \\
\text { Conditions }\end{array}$ & Ambient Conditions & $\begin{array}{c}\text { Support and } \\
\text { Security }\end{array}$ & $\begin{array}{c}\text { Work demands and } \\
\text { Control }\end{array}$ \\
\hline Mine gases & .331 & -.023 & .721 & -.028 & .060 \\
\hline Excessive noise & .285 & 681 & .002 & .047 & .095 \\
\hline Mine fires & .157 & -.213 & .700 & .168 & .042 \\
\hline Heat stress & .281 & 648 & .370 & .114 & -.059 \\
\hline Dusty conditions & .093 & .664 & -.149 & 141 & .264 \\
\hline Use of machinery & .833 & .248 & -.012 & .253 & .207 \\
\hline Hand tools & .819 & .179 & .134 & .129 & .088 \\
\hline Poor ventilation & -.106 & .295 & 637 & .067 & -.089 \\
\hline Dangerous driving & .684 & .109 & .223 & .026 & .285 \\
\hline Poor visibility & -.301 & 693 & .389 & -.050 & .341 \\
\hline Support from colleagues & .124 & .026 & .107 & .888 & .105 \\
\hline Support from supervisors & .036 & .047 & .084 & .841 & .266 \\
\hline Job security & .309 & .377 & .001 & .603 & .117 \\
\hline Workload & .132 & .422 & -.095 & .045 & .802 \\
\hline Clear roles and responsibilities & .291 & .129 & .094 & .190 & .794 \\
\hline Control over work tasks and pace of work & .161 & .044 & .003 & .388 & .682 \\
\hline$\%$ of variance explained & $23.09 \%$ & $20.47 \%$ & $17.14 \%$ & $35.73 \%$ & $31.43 \%$ \\
\hline Cronbach's Alpha & .77 & .69 & .56 & .74 & .72 \\
\hline
\end{tabular}


Table 2: Varimax Rotation of Two Factor Solution for Quality of life items

\begin{tabular}{|c|c|c|}
\hline \multirow[t]{2}{*}{ Item } & \multicolumn{2}{|c|}{ Component } \\
\hline & $\begin{array}{l}\text { Resource dependent } \\
\text { quality of life }\end{array}$ & $\begin{array}{c}\text { Society determined } \\
\text { quality of life }\end{array}$ \\
\hline Mining workers are unable to spend on the welfare of their families due to limited earnings & .728 & .197 \\
\hline Mining workers find themselves too tired at the end of the day to spend quality time with their family & .673 & .071 \\
\hline Lack of recreational activities is the main cause of unhealthy habits amongst mine workers & .651 & -.003 \\
\hline Most mine workers work under the burden of heavy loans from employers and relatives & .633 & -.052 \\
\hline Mining workers may take "bitters" and illicit drugs to reduce the stress associated with their job & .630 & .074 \\
\hline In spite of long hours of work, mining workers are considered to be highly underpaid & .524 & -.013 \\
\hline The mining job does not guarantee an acceptable status in the society & .453 & .224 \\
\hline Working in the mines has enhanced the quality of life of mine workers & -.079 & .880 \\
\hline Working in the mines has made mine workers better off than before & .136 & .814 \\
\hline Mine workers have high social status in the community & .049 & .746 \\
\hline$\%$ of variance explained & $27.41 \%$ & $23.02 \%$ \\
\hline Cronbach's Alpha & .74 & .78 \\
\hline
\end{tabular}

